\title{
A Sense of Place within Landscape Cultural Settings
}

\author{
Nik Mastura Nik Mohammad, Masran Saruwono, \\ Shahrul Yani Said, Wan Ahmad Halawah Wan Hariri \\ Faculty of Architecture, Planning and Surveying, \\ Universiti Teknologi MARA, Malaysia \\ nikmasturanikmohammad@yahoo.com.sg, mbsaruwono@yahoo.co.uk
}

\begin{abstract}
This paper presents an on-going progress of a study on landscape elements in the context of culture. The study has sought to discover people's perception, experience and responses towards their surroundings based on elements that relate to their culture and norms. Eventually, new developments do not seem to recognize and respect the importance of cultural aspects resulting disoriented buildings. An extensive reviewed of the literature was conducted to rediscover the fundamental notions of place, perception and experience. Therefore, the background review to structure the work concluded places that add value contribute to establish the urban setting and place context.
\end{abstract}

Keywords: place; character, experience; culture;

eISSN 2514-751X @ C 2018. The Authors. Published for AMER ABRA cE-Bs by e-International Publishing House, Ltd., UK. This is an open-access article under the CC BY-NC-ND license (http://creativecommons.org/licenses/bync-nd/4.0/). Peer-review under responsibility of AMER (Association of Malaysian Environment-Behaviour Researchers), ABRA (Association of Behavioural Researchers on Asians) and CE-Bs (Centre for EnvironmentBehaviour Studies), Faculty of Architecture, Planning \& Surveying, Universiti Teknologi MARA, Malaysia DOI: https://doi.org/10.21834/aje-bs.v5i19.60 


\subsection{Introduction}

This discussion contain a review of the literature on the sense of place within landscape cultural settings and gives a comprehensive account of many definitions has been known explain of place. A literature review of 13 articles published between 2001 and February 2013 and 6 book reviews is identified 3 dimensions of visual, psychology and spiritual aspects of sense of place. Some studies analysed the role of the place plays an important role in respect to cultural settings and people experience. This review of literature found that the term 'place' is defined as space states between people and the environment setting. The interpretations of reviewed studies of those prominent authors not only tell places that haven a value and uniqueness character as part of the important issue in environment behavior study. The reason why an axiom of "Sense of place" brings to places as a whole set of cultural settings is how we respond to the place. Each place has its own unique character and place meaning. Therefore, sense of place is an important aspect in cultural context in integrating user and place. Other studies focused on the effects of how people 'feel and appreciate' space and place and other related contributions. By providing an axiom for the use of the term of "sense of place," we review some of the definitions and theory used by various authors, who are affiliated with the field of behavior studies, such as landscape architects and urban designers and summarizing and expanding on a few of the ideas presented from the last conferences. The remainder of the paper is organized as follows: Section 1.1 literature on the sense of place in three dimensions and study reviewed results are presented in Table 1 and Figure 1; Figure 2 concludes the paper. Instead of thinking about identity of place as the importance of place, writers also suggest the researcher should understand place or cities as overlaid sets, subsets, infinite possibilities of interactions. In many ways, the reason why this writing reflects the current overview being offered by anthropologist, landscape architects, and architects and other urbanists.

\subsection{LITERATURE REVIEW}

\section{Sense of Place}

Research has also been carried out that sense of place can be generally described and experienced in a number of different dimensions. The description of these dimensions as found in the literature has been varied, but the following these dimensions have appeared, namely, the psychology, spiritual and visual (e.g. (Thwaites \& Simkins, 2007), (Carmona, Heath, Oc, \& Tiesdell, 2010), (Gordon Cullen, 1995), (Tuan \& Hoelscher, 1977, 2011). The following definitions give the meaning of each of these dimensions.

\subsection{Sense of Place In Relation To Psychology Dimension}

In his classic critique of the sense of place Thwaites (Thwaites \& Simkins, 2007) also found a chronology that distinguished the related of experts and others. Based on the experts directly tell a place, in this sense of place is to look how people perceive and a way of seeing. That is the human response, which, like localities and visitors, has their own "feeling" (p. 143). 
Table 1 shows the roles of the notable authors include to those points added spiritual dimension that achieve a unique sense of place. The concept of the humanistic and geographers, like Tuan and Hoelscher, have their own "hierarchy of identity and placelessness" (p. $5 \& 6$ ). The theory of the experts include significant activities (human and local), exploring space related to place to man's physical environment (academia and practice), and contribution of place attachment. Cullen (Gordon Cullen, 1995) argues that to achieve a unique sense of place, individual townscape elements should be designed as part of a whole. To those points are added a historical dimension and an exploration of the theoretical positions of Schulz and Lynch (Norberg-Schulz, 1976) \& (Kevin Lynch, 1998). This view is supported by Steele (Steele, 1981) who writes the experience that people perceive in the sense of place.

In sum, these definitions clearly indicate that the sense of place meaning of each of the terms referred to people's experience, human response and people's perception. In intermediate theories of place with more experience than the others belief is referred to people's perception, people's experience and human response. The studies of S.O.P. (sense of place) covered with cultural issues significant to human physiology and behavior activity. A relationship exists between an individual's working memory and their ability to the sense of place of feeling stimulated, excited, joyous, and expansive and so forth.

\subsection{Sense of Place In Relation To Spiritual Dimension}

Several studies investigating sense of place in relation to the spiritual dimension have been carried out as a part of characteristic research study during the last researches on how to make the retain identity of the place that represent three diverse geographical, cultural and spiritual settings, but they perform similar functions that provide a unique sense of identity and place meaning (Nik Mastura Nik Mohammad, 2012a). Sense of place is rich in theory and have own rich characteristic which makes easy for people to recognize city uniqueness due to a strong sense of place. The definition "sense of place" includes where the meaning and physical elements similar to people experiential place representing beliefs and about their memories. The definition "sense of place" includes where the meaning and physical elements similar to people experiential place representing beliefs and about their memories. Clearly, this shows that by experiencing with these great cities from different diverse cultural geography settings explore on what makes these places meaningful (Nik Mastura Nik Mohammad, 2012b). (Table 1) Other studies have considered the relationship to places and people's experience, people's perception and people's response to the setting. Such experiences reflect Tuan's theories relating to the human characters, how they form attachments to home and surroundings, their feelings about space and place that affected by the sense of time. As Cullen (G. Cullen, 2012) argues on what to achieve as a unique sense of place, individual townscape elements that should be designed as part of a whole. In this regard, taking a cue from the qualities of pre modern towns and the purpose of designing places not only facilitating of daily activities but providing symbolic and affective qualities is more important to bring people to the place. Some of environmental psychologist also argue the experience of place is one the most important factors in the sense of place. 
The ideas of spirit within the place or character of place make up the sense of place, and how feelings like stimulated, excited, joyous are an example of this experience. A place is just not an object, but through the area and experience of meaningful activities. To the authors' knowledge, the experience is felt through all the sense such as sight, smell, hearing, taste and touch by Tuan (Tuan, 1974) has been scarcely discussed from the theoretical point of view. They also have found such as Carmona (Carmona, de Magalhães, \& Edwards, 2002) mentioned the significant elements of what value urban design-economic, social and environmental. Thus, a relationship is formed between people and place inside a particular locality.

\subsection{Sense of Place In Relation To Visual Dimension}

Table 1: Concepts of place

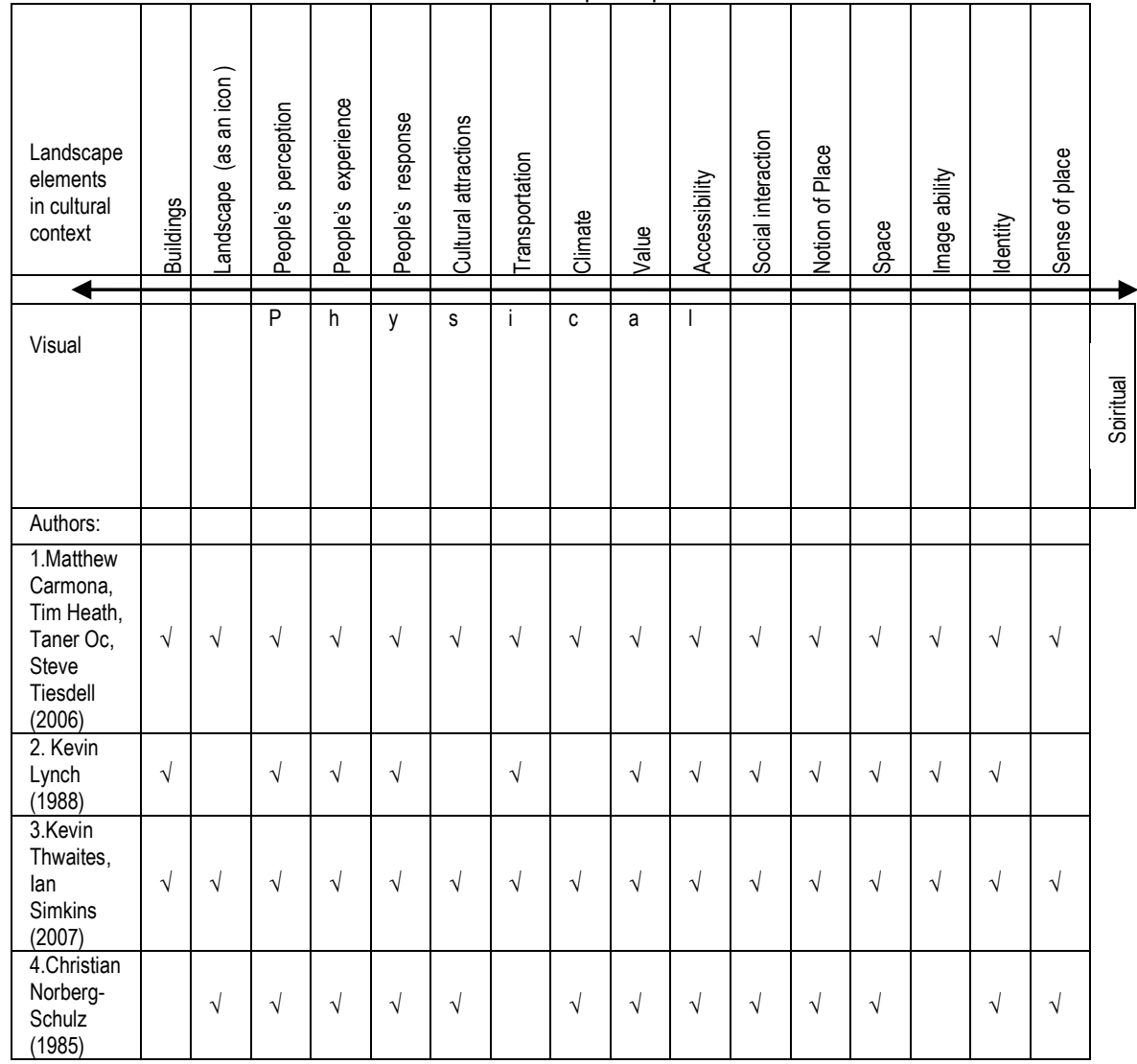




\begin{tabular}{|c|c|c|c|c|c|c|c|c|c|c|c|c|c|c|c|c|}
\hline $\begin{array}{l}\text { 5.Gordon } \\
\text { Cullen } \\
\text { (1971) }\end{array}$ & $\sqrt{ }$ & $\sqrt{ }$ & $\sqrt{ }$ & $\sqrt{ }$ & $\sqrt{ }$ & $\sqrt{ }$ & $\sqrt{ }$ & $\sqrt{ }$ & $\sqrt{ }$ & $\sqrt{ }$ & $\sqrt{ }$ & $\sqrt{ }$ & $\sqrt{ }$ & $\sqrt{ }$ & $\sqrt{ }$ & $\sqrt{ }$ \\
\hline $\begin{array}{l}\text { 6.Yi-Fu } \\
\text { Tuan } \\
\text { (Seventh } \\
\text { printing, } \\
\text { 2011) }\end{array}$ & & & $\sqrt{ }$ & $\sqrt{ }$ & $\sqrt{ }$ & $\sqrt{ }$ & & & $\sqrt{ }$ & $\sqrt{ }$ & $\sqrt{ }$ & $\sqrt{ }$ & $\checkmark$ & & $\sqrt{ }$ & $\sqrt{ }$ \\
\hline
\end{tabular}

In Table 1, it was shown that the idea of dimensions of visual such as buildings has become very popular topic to bring up the character of the place. In regards to personal history, person's images by experiencing the visual attributes of localities. As Malaysians, we have been overcome with western national myths about their history. Those images in films and articles and books reviewed shape our perceptions and expectations about places and tells us how to relate to their places. Preliminary work on visual was undertaken by Kevin (2007) how important the building heights in the design of the city and with the certain image of the city affected. However, a number of studies have found that the idea of three dimensions has overarching from those three notable authors, such as Carmona, Cullen and Kevin. To outcome, the methodology was used in the S.O.P in relation to visual is most appropriate to the place.

In sum, the three dimensions described above are obviously essential in make up the general framework establishing the behavioural studies aspects of place in the cultural context of the sense of place study. The idea of three dimensions such as visual, physical and spiritual necessary visually need to test the mechanism and attributes of these concepts of sense of place for a city landscape. In parallel, Tuan highlighted the significant localities makes an arising from human physiology and behavior activity. The sense of being home is significant with place making, place relations, texture and culture.

\subsection{Methodology}

This particular research on the selected authors for a place theory has recently been presented in Figure 1 is the important stage for seeking and discovering people's experience, people's perception and people's response towards theirs surroundings based on elements that relate to people's relationships with places. However, several practical questions arise when dealing with place. In this level, place discussions are important starting researches since the place provide rich meanings for study. In cultural context study, Tuan influenced culture learning to know the neighborhood that requires the landmark significantly identified. It is important to identify the sense of place strongly influenced by the existence of significant overwhelming the image of the city is rather unique for each city of different characters and culture. In parallel of the author reviews, the work of Lynch (K. Lynch, 1960) found a good relationship between people and place. It is the key to predict that sense of place also can be defined as a combination of physical (location of place), people experience and the locality setting. Cullen argued that to achieve a unique sense of place, part of townscape should be part of the design and details seen to have a life of their own setting. They satisfy their needs 
through emotional response in landscape and urban settings through experiential approach. Indirectly, for Cullen and Norberg-Schulz using terms such as 'spirit of place' or genius loci which has been transformed the Architectural Review passionate into an analytical and design tool such as a form of buildings, natural soft elements; trees, water elements and so on and possess the area. Afterwards, the theoretical framework had been the basis from which Kevin et al. (2007) explored and reviewed, and theory and framework used to structure of works and detailed findings of the study. In a recent book by Kevin Lynch explored the aspect of the physical setting appropriateness entire the city cohesively. Each discipline tends to have its own favored methods. By contrast, the perceptual theory holds that perception is indirect experiential landscape, but several approaches might be useful models. The points to issues of study are multisensory which explore how perception influences decision making and action. Extensive literature components on place and space collaboration focus remained defined. Books published articles and journals from others professional papers and relevant information from related internet websites remained high as the main sources for the research write-up and these were used to establish the literature framework of this research. The collective literature and precedent review are catering for future reference that will ensure the endurance and continuation of culture and place. The study concluded places that add value contribute to establish the urban setting and place context. However, to the authors' best knowledge; very few publications can be found and available in the literatures that discuss the issue of sense of place. Reference from the authors analyses and compares various aspects of place and space, behavior place and as place identity. It is crucial to addressed as in Figure 1. To answer all these questions, we present an original approach which conventional in all situations, little attention has been paid to place and space behavior. (See also Table 1)

\begin{tabular}{|c|c|c|c|c|}
\hline & $\begin{array}{l}\text { Experiential } \\
\text { Place/Space }\end{array}$ & $\begin{array}{l}\text { Cultural } \\
\text { Place/Space }\end{array}$ & $\begin{array}{l}\text { Behaviour } \\
\text { Place/Space }\end{array}$ & $\begin{array}{l}\text { Socio } \\
\text { economic } \\
\text { space }\end{array}$ \\
\hline \multicolumn{5}{|l|}{ Authors: } \\
\hline $\begin{array}{l}\text { Matthew Carmona, Tim } \\
\text { Heath, Taner Oc, Steve } \\
\text { Tiesdell (2006) }\end{array}$ & Places & Places & $\begin{array}{l}\text { Landmark, District, } \\
\text { Path }\end{array}$ & Sites \\
\hline Kevin Lynch (1988) & Places & Places & $\begin{array}{l}\text { Landmark, District, } \\
\text { Path }\end{array}$ & District \\
\hline $\begin{array}{l}\text { Kevin Thwaites, Ian Simkins } \\
\text { (2007) }\end{array}$ & Places & Places & $\begin{array}{l}\text { Landmark, District, } \\
\text { Path }\end{array}$ & District \\
\hline $\begin{array}{l}\text { Christian Norberg-Schulz } \\
\text { (1985) }\end{array}$ & Places & Places & Environments & Sites \\
\hline Gordon Cullen (1971) & Spaces & Spaces & Spatial layouts & Landmark \\
\hline $\begin{array}{lrl}\text { Yi-Fu } & \text { Tuan } & \text { (Seventh } \\
\text { printing, 2011) } & \end{array}$ & Spaces & Spaces & Environments & Sites \\
\hline
\end{tabular}

Figure 1: Summary of previous research of the different kinds of notions of places and space. 


\subsection{What the authors perceive}

Based on the approach presented in Table 2 and Figure 1, most of the discussion, theory philosophy reviewed, and theory and framework used to structure of works and detailed of the findings. The study concluded places that add value contribute to establish the urban setting and place context. Like most authors, we reviewed that literature reveal a sense of place has different levels. These findings have important consequences for the broader domain of what other authors really means is focusing on the basic components of a communicative study has three different levels of scale as centre, direction, and transition and area using symbol. The paper deals with the existence sense of place are related to cultural variables, such as religious and ethnic background. Shamai is right that seven levels were categorized from the three major-belonging to a place.

\subsection{Not having any Sense of place}

- Belonging to a place: this stage, people not just familiar with the place but also familiar with the place. They distinguish symbols of place, and in contrast it respected.

- Attachment to a place: at this stage people had strong emotional relationship with place. The place is meaningful and so significant to people. Regards to the uniqueness identity and character to the users and possess the meaningful symbols.

- Identifying with the place goals: this level people integrated with place.

- Involvement in a place: the level people invest their resources such as time and money or activities of the place.

- Sacrifice for a place: the highest level of Sense of place that people would sacrifice of important attributes and value such as prosperity, freedom, or life itself.

Section of seven levels outlines, the three dimensions overarching forms the important attributes of sense of place identified in Table 1 can be understood to cross-cut the four different kind of notion of place (from Figure 1).

A collection of subsets in Figure 2 above which goes to make a picture of relationships are established among the subsets once the subsets are chosen, and the collection has a definite structure of the authors. To understand this structure by labeling these elements 1 , 2, 3, 4, 56 from the authors reviewed. The following questions will be addressed what are the possible relationships among this set. The structure illustrated in both diagram satisfies the axiom since the characteristics is defined. However, in this paper the writer are not so much concerned with the fact that a structure diagram happens to be, but the contain overlapping units do occur. These overarching have forms of the significant to the value such as prosperity, freedom and life as stated by Shamai (1991). However, it was understood that the cross-cut means that the significance arising from human experience and behavioral activity as mentioned by Kevin (2007) localities by Tuan $(1977,2011)$. Several publications 
have appeared in recent years documenting of love landscape is an essential part of the belonging to a "place" on how people value the "place to place". In the 2000s, under the perception of the notion of place, researcher started examines the experiential place. In author perspectives, the role as a researcher must understand the best ways in which the community gathers the nature of the genius loci's community and its traditions of built form. Among others, the views of urban designers and stake holders in particular need to analyses the authenticity of the place, sense of place, and character. This study aims to seek these arguments of sense of place in relation to how people perceive the place today yet, it challenges the ways in notions of place. This study proposes a new approach to landscape architectural as part and human responses to inhabited landscape and their "place."

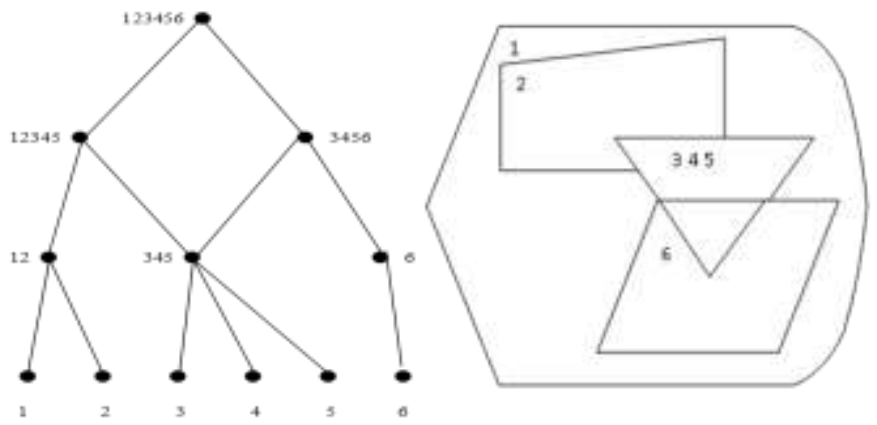

Figure 2 Visual diagrams of six authors and different groupings can be seen as the structures above.

\subsection{Results and Discussions}

\subsection{The factors contributing to the sense of place}

The place subjective on the people perceive and natural environments about this sense of place. The emotional aspect of experiencing the place means the dimension of physiological and physical interaction. Lynch (1998) explained that a contribution belongs to the first generation of works in environmental psychology and environmental behavior. The combinations of physical and social attributes creates the environment between people and environment from negative or positive from the place and tell to the environment. Steele (Steele, 1981) described that people tend to experience with certain setting from the strong character of the place. Tuan $(1977,2011)$ highlighted the people feeling of time and their surrounding such as home. The contributions from the outside professionals and inside users view differently. Carmona (2010) as a group researcher explained, in order to provide a broader understanding of good urban design, and preservation stressing on the nature setting. To suit various purposes such as the pattern of the place, the stories of place tell us the character of the place. Lynch (1998) described the method of environmental psychology 
included cognitive mapping as one of the components in a research study. As a result, there are varied sense of place between people and their experiences and their background; also the place characteristics of the physical setting influence the sense of place. Kevin and lan (2007) stated the scale, centered, direction and transition area are most significant aspects of place character. Therefore reviewed literature revealed that the physical features of place creating the meaning and character that contribute to make sense of place. With understanding meanings and concepts, symbols and identity of place cognitive and effectiveness of place bonds with place. Stedman (Stedman, 2002) argued that the sense of place definition is very difficult to define. Figure 3 is the idea of five elements such as landmarks, districts, buildings, sites and monuments as necessary image visually needed to test the mechanism and attributes of these elements for a city landscape. The researcher acknowledges through the understanding of the value is significant to the issues of sense of place and image ability. The processes of selection from the resources and understanding of the targeting the identity revealed a value with respond to the space.

As may be seen, above in Figure 3, the process of selection and targeting of the sense of place relies on understanding of values. This approach is due to the values, and the overall measurement results are summarized in Figure 3. There is a good match between selection of resources and targeting the forms of attractions and identity of place. As a place can be described as bonding people to places and influenced by psychological approach explained by Altman (Low \& Altman, 1992). The author's attention was focused not only on the existing resources such as buildings, sites, landmark, and monuments. In this regard, reviewed literatures explained that place affected by several factors as follows: Experiences including (Bradley, 2002; Catharine Ward Thompson, 2007; G. Cullen, 2012; Gordon Cullen, 1995; Middleton, 2009; Sim, 2011; Thwaites \& Simkins, 2007; Tuan \& Hoelscher, 1977, 2011). A novel view of the degree of familiarity with a place plays an important role in a sense of place and place meaning in some of the studied reviewed. Familiarity includes recognizing by entering it or being there. The most likely explanation of how human perception results such as similar to some of the place in our memory as to a visual impact and drama. These conclusions, which Kevin discusses in experiential the place, add weight to the argument that peoples response or knowledgeable about the place; because their expertise about the environment and place by looking at in differently.

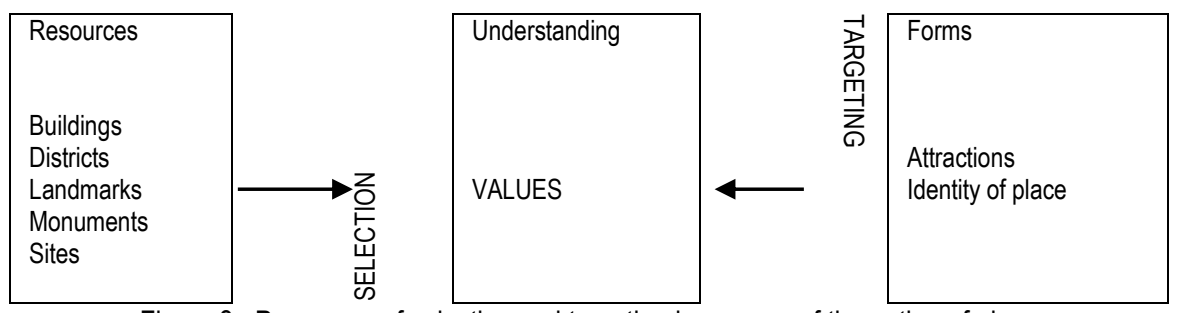

Figure 3: Processes of selection and targeting in a sense of the notion of place 


\subsection{Culture}

Culture; (Tuan, 1974; Tuan \& Hoelscher, 1977, 2011) literatures have emphasized the used of culture on people relationship with places. The truth of a new term known as "topophilia" has no single sense of place, instead of responses to the environment. The essence of Tuan's argument is that understanding of place is through a psychology observation of human bond between people and place. Zeisel (Zeisel, 1984) described an identity itself is one of the most difficult concepts to define because it refers to the relationship of the self to the environment. My own view is that what Zeisel insists is a part of a person's total identity involves identification of places, whereas people fight for the identity places. In 1960, Lynch, in his perceptive article, sees identity as being the simplest form of sense, of which the narrow meaning of the term is a sense of place. It is tempting to credit many of the succeeding changes to Relph remind us that place reflected by the notion of identity as being an expression of adaptation, assimilation, accommodation and socialization of knowledge of each other. However, the new methods shall be viewed within the context of the identity of place and is always the very basic of our experience of the place as opposed to any other. To say, this is to point to wider implications for the image of place is its identity and to understand something of the social structure and culture structure of image ability is an essential prerequisite in understanding identity. The most important part of identity cannot simply relate to the distinctiveness of the physical environment and the ability for it to be recognized or recalled vividly by the observer. They may also sometimes point to shared geographical setting is the other aspect of location that has a strong influence to the identity of place. It is necessary to adopt adding values to place an essential part in understanding the identity and character of the place.

\subsection{Conclusion}

The context of culture investigated, there is a need for continued research and application of high combination of physical, visual and spiritual within the place appropriate at their place making and contribute to the sense of place. Even the selective authors knew that sense of place in relation to people and places. Previous studies indicated that attributes in the study has covered three dimensions such as physical, visual and spiritual associated with places contribute to sense of place. The existence of the place was supporting the particular action and activities, meanings can be referring as perception that people perceived sense of place. The people past experiences, background, belief, culture influenced and perceived sense of place. However, places have different levels of sense of place that contribute to social activities based on the relationships of place meaning. Most study on places and their meaning is the important issue in the built environment. Regards to the new development and issue of change in the contemporary context, placelessness described as what contribute to the place. The full paradigm of how people's experiences of places and this includes the related of character and legibility, physical and behavioral activity that comprise our emotional relationships to places. Clearly, further study will be needed on how people's experienced on environment involves the degree of familiarity with place and expertise in 
their own knowledge about the place is still necessary before obtaining a definite answer to what is a sense of place. The next stage of our study will be experimental confirmation of our theory.

\section{Acknowledgement}

The authors would like to acknowledge the valuable comments and suggestions of the reviewers, which have improved the quality of this paper. An earlier version on this study was presented at AicE-Bs Conference 2013 of cultural theme in cultural sustainability in the built and natural environment in Hanoi, Vietnam. I am grateful for comments made by the chairperson and participants at the conference and also to my supervisors.

\section{References}

Bradley, Richard. (2002). The significance of monuments: on the shaping of human experience in Neolithic and Bronze Age Europe: Routledge.

Carmona, Matthew, de Magalhães, Claudio, \& Edwards, Michael. (2002). What value urban design? Urban design international, 7(2), 63-81.

Carmona, Matthew, Heath, Tim, Oc, Taner, \& Tiesdell, Steve. (2010). Public places-urban spaces. Oxford: Architectural Press.

Catharine Ward Thompson. (2007). OPEN SPACE: PEOPLE SPACE Catharine Ward Thompson and Penny Travlou (Ed.)

Cullen, G. (2012). Concise Townscape: Routledge.

Cullen, Gordon. (1995). Concise Townscape: Routledge.

Low, Setha M, \& Altman, Irwin. (1992). Place attachment: Springer.

Lynch, K. (1960). The image of the city (Vol. 1): MIT press.

Lynch, Kevin. (1998). Good city form. Mass: The MIT Press.

Middleton, J. (2009). 'Stepping in time': walking, time, and space in the city. Environment and Planning A, 41(8), 1943-1961.

Nik Mastura Nik Mohammad, Masran Saruwono. (2012a). Exploration of Sense of Place of York, Istanbul and Bangkok. Science Direct, 10.

Nik Mastura Nik Mohammad, Masran Saruwono. (2012b). Exploration sense of place for an old city district of York, Istanbul and Bangkok. Science Direct(10).

Norberg-Schulz, C. (1976). The phenomenon of place. Architectural Association Quarterly, 8(4), 3-10. 
Nik Mohammad, N.M., et.al. / Asian Journal of Environment-Behaviour Studies (ajE-Bs), 3(9) Jul / Aug 2018 (p3-14)

Seamon, David, \& Sowers, Jacob. (2008). Place and placelessness, Edward Relph. Key texts in human geography, 43-51.

Sim, Jeannie. (2011). Explorations in landscape design theory: designed landscapes and cultural landscapes. Australian Garden History, 22(4), 19.

Stedman, Richard C. (2002). Toward a Social Psychology of Place Predicting Behavior from Place-Based Cognitions, Attitude, and Identity. Environment and behavior, 34(5), 561-581.

Steele, Fritz. (1981). The sense of place (Vol. 87): CBI Publishing Company Boston, MA.

Thwaites, K., \& Simkins, I. (2007). Experiential landscape : an approach to people, place and space. London [etc.]: Routledge.

Tuan, Yi-Fu. (1974). Topophilia: A study of environmental perception, attitudes, and values: Columbia University Press.

Tuan, Yi-Fu, \& Hoelscher, Steven. (1977, 2011). Space and place: The perspective of experience (Seventh ed.). Minneapolis: University of Minnesota Press.

Zeisel, John. (1984). Inquiry by design: Tools for environment-behavior research (Vol. 5): Cambridge University Press. 